\title{
Determinants of bank efficiency during unstable macroeconomic environment: empirical evidence from Malaysia
}

\begin{abstract}
The present study investigates for the first time the efficiency of Malaysian banking sector around the Asian financial crisis 1997. The efficiency estimates of individual banks are evaluated by using the Data Envelopment Analysis (DEA) approach. To examine the robustness of the estimated efficiency scores under various alternatives and to differentiate how efficiency scores vary with changes in inputs and outputs, the present study focuses on three major approaches viz., intermediation approach, value added approach, and operating approach. The analysis further links the variation in calculated efficiencies to a set of explanatory variables, i.e. bank size, profitability, and ownership. The empirical findings clearly bring forth the high degree of inefficiency in the Malaysian banking sector, particularly a year after the East Asian crisis. The results suggest that the decline in technical efficiency is more abrupt under the intermediation approach relative to the value added approach and operating approach. The regression results focusing on bank efficiency and other bank specific traits suggest that efficiency is negatively related to expense preference behavior and economic conditions, while bank efficiency is positively related to loans intensity.
\end{abstract}

Keyword: Financial crisis; Bank efficiency; Malaysia 